\title{
Fauna amazônica: um estudo etnoterminológico sobre indicadores culturais na obra Chuva Branca
}

\author{
Amazon fauna: an ethno terminological study on Chuva Branca cultural indicators
}

Livia Regina Fernandes SOUZA* Universidade Federal do Pará (UFPA)

Sílvia Helena Benchimol BARROS** Universidade Federal do Pará (UFPA)

Tabita Fernandes da SILVA*** Universidade Federal do Pará (UFPA)

RESUMO: Este artigo propõe um estudo etnoterminológico de unidades do léxico constituinte da obra Chuva Branca (1968) de Paulo Jacob. Apresenta uma análise de oito vocábulos-termos referentes à fauna amazônica, destacando a importância destes para a cultura ribeirinha amazônida. Prevalece o argumento de que o corpus de análise, inserido na realidade específica apresentada na obra, é fortemente marcado culturalmente e capaz de interferir nos comportamentos dos indivíduos e em suas práticas cotidianas. Subliminares à analise estão concepções teóricas voltadas às ciências do léxico (VILELA, 1994; BIDERMAN, 1981, 2001); e, especificamente, da Etnoterminologia (BARBOSA, 2005; 2006). Outros autores dão suporte às reflexões sobre a obra literária (SOUZA, 2015; COUTINHO, 1978). Quanto aos aspectos amazônicos, contribuíram estudos de Schontag (2015) e Peixoto (2009). Os resultados reforçam a estreita relação entre léxico e cultura, e os vocábulos-termos como veiculadores de saberes coletivos e como símbolos de temas do cotidiano dos indivíduos ribeirinhos amazônidas.

PALAVRAS-CHAVE: Chuva Branca. Léxico. Cultura. Etnoterminologia.

ABSTRACT: This paper proposes an ethno terminological study of selected lexical units from Paulo Jacob's work Chuva Branca (1968), presenting an analysis that highlights their importance for the Amazonian riverside culture. The prevailing argument is that the corpus, inserted in the specific reality presented in Chuva Branca, is strongly culturally marked and

\footnotetext{
* Mestre em Linguagens e Saberes na Amazônia pela Universidade Federal do Pará, Bragança- PA. Email: liiviinha2009@yahoo.com.br

** Doutora em Tradução e Terminologia pelas Universidades de Aveiro (UA) e Nova de Lisboa (UNL), Aveiro/ Lisboa- Portugal. E-mail: silviabenchimol@ hotmail.com

*** Doutora em Linguística pela Universidade de Brasília, Brasília- DF. E-mail: tabitafs1 @ hotmail.com
}

Revista Moara, n. 55, jan-jul 2020 ISSN: 0104-0944

Recebido em 2403/2020

Avaliado em 02/06/2020 
capable of interfering in the behaviors of individuals and their daily practices. Subliminal to the analysis are theoretical conceptions from the Lexical Sciences (VILELA, 1994; BIDERMAN, 1981, 2001; and, specifically, from the Ethnoterminology (BARBOSA, 2005; 2006). Other authors support reflections on the literary work (SOUZA, 2015; COUTINHO, 1978). Regarding the Amazonian aspects, the main contributions were Schontag's (2015) and Peixoto's (2009). The results of the research reinforce the solid connection between lexicon and culture, and the ethnoterms as carriers of shared knowledge and symbols of quotidian issues of the Amazon riverside people.

KEYWORDS: Chuva Branca. Lexicon. Culture. Ethnoterminology.

\section{Introdução}

Na década de 60, especificamente no ano de 1968, o autor Paulo Jacob publicou uma de suas principais obras, o livro Chuva Branca. Marcado por traços regionalistas, a obra tem como intuito denunciar os descasos sociais que atingem a realidade dos ribeirinhos amazônidas. Uma floresta desamparada, ameaçada pelos interesses políticos e desvalorizada sob a perspectiva dos saberes que abriga é revelada na narrativa que expõe, nos capítulos de Chuva Branca, aspectos positivos e negativos da realidade da Amazônia, o que faz do romance uma das principais referências literárias dessa região. ${ }^{1}$

A ocupação da Amazônia teve início com os imigrantes asiáticos, no século XIX, quando, após a colonização, o território ficou marcado pela miscigenação. Brancos, índios e negros trabalhavam em torno do ciclo da borracha, o que favoreceu o crescimento econômico dos mercados, em especial dos que pertenciam às nobres famílias de Manaus e Belém. Após reconhecido apogeu, em meados do século XX, o ciclo da borracha entrou em declínio, causando o esquecimento da Amazônia, então vista sob a ótica capitalista e extrativista. Assim, a partir de 1960, o governo federal investiu nas ações de integração nacional sob o mote "Integrar para não Entregar" (PEIXOTO, 2009), na criação do Programa de Integração $\mathrm{Nacional}^{2}$, e na criação de

\footnotetext{
${ }^{1}$ A obra Chuva Branca de Paulo Jacob deu origem a dezenas de trabalhos que a abordam sob diferentes perspectivas: social, ambiental, cultural, linguística (SOUZA, 2015; SAMUEL, 2008; LOURO, 2007)

${ }^{2}$ PIN - Programa de Integração Nacional - Programa governamental instituído pelo Decreto-Lei no ${ }^{0} .106$, de 16 de junho de 1970, durante o governo do general Emílio Garrastazu Médici. Tinha por objetivo implementar obras de infra-estrutura econômica e social no Norte e no Nordeste do país.
} 
projetos e incentivos fiscais, significativos para atrair a atenção de investidores e de imigrantes.

Como desdobramento do novo cenário, uma sucessão de consequências transformadoras aflora, principalmente na paisagem do território, que precisou ser devastada para a construção de estradas. Este período é marcado pela construção da BR010, que liga as cidades de Belém e Brasília, e da BR- 364, que liga Cuiabá a Rio Branco.

\begin{abstract}
A BR-010 (Belém- Brasília) foi a propulsora da agricultura, da pecuária, e do consequente aumento da população da Amazônia a partir da década de 1960. Essa rodovia reduziu o custo para o estabelecimento de migrantes, facilitou viagens para o resto do país e tornou o transporte dos produtos agrícolas mais baratos. A BR-364(Cuiabá-Rio Branco) desencadeou a maior migração para territórios virgens da história da América do Sul. (...). Essas estradas promoveram a intensificação de atividades agropecuárias, a exploração mineral (cassiterita) e o estabelecimento de muitos aglomerados populacionais. (IMAZON, 2015).
\end{abstract}

Ainda em 1960, foram criados projetos que incentivavam a agropecuária e a mineração em busca de alumínio e manganês. Tais projetos provocaram crescimento urbano e populacional com a chegada dos imigrantes, impactos ambientais e sociais e o avanço de conflitos, mudanças que influenciaram a reconfiguração dos espaços.

Nesta mesma década, foi criada e aprimorada a Zona Franca de Manaus (SCHONTAG, 2015, p.1). A ocupação das áreas florestais que, de início, restringia-se às margens das estradas, evoluiu para os interiores a partir da década de 70, e os benefícios advindos da Amazônia favoreciam a sociedade abastada, apesar do crescente fluxo migratório na região (PEIXOTO, 2009).

Este retrospecto sócio-histórico tem por objetivo realçar os descompassos das realidades coexistentes em um mesmo território, pois, diante de tantos "avanços" e da disseminação de políticas públicas que atendiam aos interesses capitalistas e visavam mudanças convenientes aos grupos de poder, emergiram consequências danosas, ainda hoje vivenciadas, como o desmatamento e o vilipêndio do modo de vida de populações tradicionais. $\mathrm{O}$ homem ribeirinho continuou entregue ao descaso e ao abandono em suas necessidades mais básicas, situação que se reflete na inquietação que Paulo Jacob expressa em suas obras e em cujo escopo destacamos Chuva Branca.

\title{
1. O contexto de produção e a obra literária
}


Paulo Herban Maciel Jacob, descendente de judeus, maranhense, filho de Josefa Maciel Jacob e Hermeto de Sá e Silva Jacob, cresceu e se formou em advocacia pela então Faculdade de Direito do Amazona - a atual UFAM. Após exercer por longo período a carreira de magistrado em sua região, Jacob foi nomeado juiz municipal de Itapiranga, no Amazonas (SOUZA, 2015). O fato de ter exercido várias funções tais como desembargador, corregedor geral de justiça, vice-presidente e presidente geral do Tribunal de Justiça e professor de Direito (SOUZA, 2015), permitiu-lhe conhecer mais de perto a realidade da população ribeirinha da região e o descaso por ela sofrido.

Segundo Mendonça (2012), entre os anos de 1971 a 2003, Paulo Jacob tornou-se um membro imortal da Academia Amazonense de Letras, tendo, em 1968, publicado seu memorável e mais consagrado romance, a obra literária Chuva Branca - corpus de referência desta pesquisa - obra que conquistou o $4^{\circ}$ lugar do prêmio Walmap. A história narra a vida do ribeirinho Luís Chato que, após sair para caçar uma anta, acaba por perder-se na floresta amazônica, imersa em mitos, superstições e crenças. Chuva Branca, desenreda a riqueza de saberes do homem ribeirinho sobre a região (SOUZA, 2015). Com um léxico marcadamente popular e localizado, a compreensão e apreciação da obra exige, do leitor, conhecimento cultural da região, além de familiaridade mínima com a linguagem peculiar local.

Silva (2010) afirma que, por meio de suas obras, o autor incita justiça, ao abordar de forma original o descaso vivenciado pelos amazônidas. Assim, revela uma forma de manifestar sua indignação diante da dura realidade vivenciada pelos ribeirinhos e ribeirinhas na Amazônia. A mata é o local que norteia todos os acontecimentos e serve como "moradia" para o protagonista da "história", Luís Chato, o qual narra todo seu sofrimento, chamando a atenção para a condição de abandono daquele grupo social.

De acordo com os estudos de Genette (1995), o narrador pode ser classificado tanto em relação ao nível narrativo, quanto à sua inserção dentro da história. Sob esta ótica, em Chuva Branca, Luís Chato participa como narrador intradiagético autodiegético, respectivamente, por se tratar de um 'narrador personagem', que conta sua história dentro do plano de ficção, e pelo fato de narrar sua própria história.

A obra divide-se em duas partes: a primeira, intitulada Chuva Branca, sendo este fenômeno umas das principais adversidades enfrentadas por Luís Chato, e a segunda, Revista Moara, n. 55, jan-jul 2020 ISSN: 0104-0944 
Mãe do rio, local indicador da possibilidade de localização do caminho de volta para casa.

Os capítulos ao longo das 229 páginas de narrativa marcante relatam a vida de um homem mateiro, sábio, orgulhoso conhecedor da mata que, ironicamente, se perde dentro de seu "próprio território". O texto é repleto de histórias e crenças sobre os universos geográfico e imaginário amazonenses. Os mitos, entre eles o do Curupira, Mapinguari e Mãe-do-rio, são parte integrante da rotina de Luís Chato, e estas presenças evidenciam a relevância dos saberes de seu povo para lidar com os eventos de enfrentamento do dia a dia. Três dimensões foram consideradas neste estudo as quais julgamos merecedoras de um olhar teoricamente respaldado e por descortinarem um rico material interpretativo: o homem, o espaço e as adversidades.

\subsection{O homem}

Parte fundamental do espaço amazônico, o homem, Luís Chato, narrador e protagonista da obra Chuva Branca, constrói uma história repleta de aventuras, crenças, mitos em sua situação de perdido na mata amazônica. Seu nome faz alusão ao desprezo e sofrimento em que vivem os povos ribeirinhos. Luís, além de representar o típico pai de família, trabalhador, responsável e preocupado, carrega o papel de esposo, com ideais e opiniões que remetem à dinâmica dos casamentos no século XX naquela região e ao papel de amigo e companheiro solidário com o próximo, em especial, com seus vizinhos.

A condição de solidão do protagonista, perdido na floresta amazônica, consegue sustentar o romance inteiro, fato que realça a força do personagem, caracterizados sobretudo, na luta pela sobrevivência sob as intempéries. Ainda que em meio a batalhas diárias contra animais, a fome, o frio, a saudade e as enfermidades que emergiam durante esta saga, Luís consegue trazer humor à trama, ao relembrar as peripécias do passado.

Embora a história vivida por Luís Chato seja marcada por uma constante batalha pela manutenção da vida e superação de percalços, é ainda a expressão de estagnação por uma busca que nunca se concretiza, na floresta ou fora dela. Sua condição humana e social não sai da mesmice, o que sinaliza de forma implícita pelo autor a inoperância das políticas públicas que em nada transformam aquela realidade, a não ser para pior, 
tirando o pouco que ainda lhe resta. Nas palavras de Jacob, o protagonista sempre dá ênfase a suas condições: "desde menino a mesma vida, apertura que nem hoje" (JACOB, 1968, p.7). Em toda a obra podemos perceber um Luís Chato que agrega o homem agricultor, pescador, caçador e lavrador. Esses papéis contribuem para a formação de um ser holístico - sábio, forte, guerreiro, sensível e experiente - que luta contra as adversidades impostas pela vida. Com isso, no decorrer da narrativa, a mata torna-se a moradia do protagonista, sendo ele indispensável e parte integrante da existência da Amazônia.

\subsection{O espaço}

O território amazônico, onde se desenrola a história Chuva Branca, é caracterizado pela biodiversidade e pluralidade sociocultural, marcado pela presença de povos indígenas e populações tradicionais de ribeirinhos, seringueiros, pequenos agricultores e pecuaristas, que se constituíram a partir do processo de colonização e miscigenação ocorrida na região. Segundo Chaves (2001), a junção desses povos contribui para a formação de um grupo heterogêneo, capaz de compartilhar das mesmas identidades sociais e políticas, fundamentadas em habilidades e saberes tradicionais, tendo como base: (i) a origem étnica por meio da adoção e adaptação de saberes e técnicas de acordo com suas necessidades; (ii) o padrão complexo de organização da produção e de gestão dos recursos naturais; (iii) a luta pela garantia de sobrevivência e acesso a bens e serviços sociais; (iv) as atividades exercidas como: agricultura, caça, pesca, coleta e extração, desempenhadas conforme as necessidades e recursos naturais disponíveis. Até a década de 60 as principais atividades econômicas das comunidades tradicionais eram a pesca e o extrativismo. Em Chuva Branca estas são enfatizadas como fundamentais para a subsistência da população.

O território amazônico mostrado na obra tem seu processo de povoamento desenvolvido ao longo dos rios e das várzeas. O autor relata um ambiente formado por rios, igarapés e uma alta fertilidade dos solos, onde são desenvolvidas atividades de lavoura e pecuária, complementadas pela caça, pesca, criação de animais, produção e extração de alimentos. Um de seus principais objetivos em Chuva Branca foi criticar as consequências de um processo exploratório desordenado, fomentado pela noção de 
progresso baseada na extração das riquezas que, progressivamente, ocasionou o desmatamento, a poluição e, sobretudo, o descaso com a sociedade local.

A Amazônia em Chuva Branca é manancial de crenças, mitos, segredos e mistérios, sustentada pelo conhecimento fundamental e tradicional do povo que nela habita. Particularizada pela abundância de frutos e animais de múltiplas espécies, habilidades peculiares de seus habitantes e simbologias culturais, a descrição da floresta faz da narrativa um exuberante acervo de informações para o conhecimento das riquezas da Amazônia. Luís Chato aborda diferentes temáticas referentes ao território, de forma minuciosa e reflexiva, revelando um conjunto de conhecimentos que se constituem patrimônio cultural e social da humanidade.

Mais de meio século após o lançamento do livro, problemas destacados em Chuva Branca, como o descaso com a população, perduram até hoje, mostrando que o território amazônico ainda carrega uma imagem de riqueza comercial, acima de qualquer outra percepção.

\subsection{Adversidades, prognósticos e mau presságio}

Luís Chato, diante da situação de penúria em que se encontrava sua família, sai à caça de uma anta, intentando resolver, não só o problema da fome, mas também o de obter recursos com a venda do animal. Todavia, o protagonista não antevia as adversidades que estariam por vir, tampouco o fato de que nunca mais veria sua família.

Ao adentrar a mata, Luís Chato tinha certeza de que a conhecia o suficiente para encontrar o animal e voltar à casa no final da tarde. No entanto, no início de sua caminhada, uma rápida e inesperada chuva branca cobriu seu caminho, dificultando a visão de seu percurso. Nenhum tipo de marcação estava sendo feita por Luís para sinalizar o caminho de volta para casa, pois sua autoconfiança de mateiro experiente não permitia qualquer preocupação e, muito menos, que atrasasse seu objetivo mais imediato.

De repente, a anta é avistada e Luís Chato atira, mas o disparo pega de raspão o animal, que sai correndo desesperadamente. Inconformado, e na certeza de que ali estaria sua melhora, persegue a caça. Entretanto, as circunstâncias pioraram continuamente até que este se percebesse completamente perdido, mas ainda assim, manteve a esperança. 
Sobrevieram-lhe a preocupação com as condições da família, o frio e o medo. A ideia de homem "bruto" e sem temor deu lugar à fome, sede, doenças e temores. A noite tornou-se martírio, as roupas desgastaram-se, o fogo extinguiu-se, as dores da alma uniram-se às do corpo, e vieram os transtornos físicos e psicológicos.

Comer o que encontrava pelo caminho, subir em árvores para se proteger, atravessar rios e matas em busca do caminho indicado pelo sol eram algumas das soluções para manter a vida e a esperança de retornar para casa. Uma situação jamais imaginada por Luiz Chato. Mitos, crenças, e elementos sobrenaturais, antes considerados sem importância, ganham dimensões reais. Elementos simbólicos da natureza indicadores de maus presságios representados pelos animais, passam a tomar conta de sua mente e a funcionar como explicações para o seu estado de desventura e

aflição. É precisamente este aspecto, da fauna como elemento controlador dos comportamentos, que este artigo se propõe a explorar sob o viés dos estudos etnoterminológicos.

\section{Vocábulos-termos referentes à fauna como indicadores culturais: um enfoque etnoterminológico}

\subsection{O léxico sob o enfoque da Etnoterminologia}

É consensual nos estudos do léxico a relação deste com a realidade histórica, ideológica, social e cultural humana (VILELA, 1994). Para Biderman (1981, p. 134) “O léxico de uma língua seria um arquivo acumulado da experiência multissecular das comunidades humanas que falavam e falam essa língua."

O estudo aqui proposto toma como aporte a Etnoterminologia, área do léxico cuja unidade básica de estudo é o vocábulo-termo, que consiste em um termo com um significado de expressivo valor cultural e influência para um determinado grupo social. Barbosa (2005) exemplifica vocábulo-termo com a palavra boi, no rito do bumba-meuboi que, no norte do Brasil, refere-se a uma dança folclórica e não ao animal.

A Etnoterminologia interessa-se pelos discursos etnoliterários tais como a literatura oral, popular, de cordel, fábulas, lendas, contos, mitos ou folclores (BARBOSA, 2009), contribuindo para a compreensão das peculiaridades dos valores semânticos dentro do discurso bem como das características socioculturais presentes na língua de determinados grupos de indivíduos (LATORRE, 2013). Isso parte do 
pressuposto de que as crenças, os costumes e os valores de uma dada sociedade estão na base da construção e utilização dos vocábulos-termos da língua praticada por essa mesma sociedade.

As unidades lexicais dos discursos etnoliterários apresentam uma significação tão específica que, para compreendê-las, seria necessário estar inserido no meio que a utiliza. Acerca do discurso etnoliterário, Barbosa (2006, p. 50) afirma que:

Essas unidades lexicais apresentam sememas construídos, em grande parte, com semas específicos do universo de discurso etnoliterário, provenientes das narrativas e cristalizados, de maneira a tornar-se verdadeiros símbolos dos temas envolvidos. É preciso estar familiarizado com as histórias, conhecer o pensamento e o sistema de valores da cultura em questão, para poder compreendê-los bem.

Barbosa (2009, p. 4) comenta sobre a vinculação que os discursos etnoliterários têm com o conjunto de valores de uma dada sociedade:

Os discursos etnoliterários se ocupam, dentre outras coisas, dos sistemas de valores que, por sua vez, determinam pensamentos e comportamentos, de formas de ver o mundo, de maneiras de agir, recomendável ou condenável, no fazer social. Esses discursos definem, assim, uma axiologia.

Por um lado, um texto narrativo como o de Chuva Branca, que objetiva representar a identidade local amazônida, tem baixo grau de cientificidade e tecnicidade, reunindo, assim, características dos discursos etnoliterários. Por outro, o fato de que suas unidades lexicais são empregadas com significados bastante particularizados, justificam seu caráter especializado. Nela, também, é encontrado um conjunto de valores que orientam e regulam a vida dos indivíduos que compartilham o espaço da Amazônia ali retratada.

Segundo Barbosa (2007), uma obra literária não apresenta o caráter da tecnicidade como aquela presente nos discursos estritamente especializados, mas também as unidades lexicais que a compõem não estão no nível da linguagem comum. Assim considerando, a autora propõe a existência do vocábulo-termo, também conhecido como etnotermo para as unidades lexicais presentes nos discursos etnoliterários. Nesse sentido, a autora chama a atenção para dois importantes fenômenos: a terminologização e a vocabularização. No primeiro caso, há um movimento de conversão 'do conceito em termo', a que ela considera equivalente ao de 
lexemização de Pottier (1992). No segundo, ocorre o processo de transformação 'do termo em vocábulo', também chamado de banalização, vulgarização e popularização (BARBOSA, 2007). Assim, o vocábulo-termo constitui-se como uma unidade de dupla face: a de termo e a de vocábulo.

Neste trabalho apresentam-se oito vocábulos-termos extraídos da obra Chuva Branca, selecionados a partir de critérios que levaram em consideração, em primeira instância, a temática central da obra: o fato de um mateiro experiente perder-se na floresta amazônica. Considerado esse fato central, os vocábulos-termos escolhidos referem-se à relação do homem, perdido na floresta amazônica, com: a) o espaço onde se perde; b) as adversidades enfrentadas no espaço; c) os prognósticos e maus presságios que lhe acompanham. Os vocábulos-termos selecionados ligam-se a elementos da realidade, seja a realidade do espaço físico da região amazônica, seja a realidade social e cultural.

\section{Vocábulos-termos referentes a elementos da fauna como indicadores culturais}

A análise dos vocábulos-termos deste trabalho não contempla os aspectos da estrutura morfológica desses elementos, nem busca mostrar os detalhes do movimento da terminologização desses vocábulos. Concentra-se, tão somente, no aspecto cultural do significado agregado a cada vocábulo no contexto específico da obra Chuva Branca que o eleva à condição de termo. Para as definições dos vocábulos-termos, utilizou-se o Dicionário Brasileiro de Língua Portuguesa Michaelis online e o Dicionário da língua popular da Amazônia (1985), do próprio escritor de Chuva Branca e, na ausência de uma definição relacionada ao contexto da narrativa, algumas delas são propostas pelas autoras deste trabalho, com base na leitura e compreensão da obra. As definiçõoes do primeiro dicionário são apresentadas, a fim de se demonstrar que estas não contemplam os significados culturais que alçam tais vocábulos à condição de vocábulos-termos. $\mathrm{O}$ segundo dicionário, por sua vez, contempla, em parte, tais significados culturais.

Algumas importantes questões nortearam a análise, a saber: a) em que contexto da obra o vocábulo-termo foi usado? b) O que torna o item lexical em análise um 
vocábulo-termo? c) qual a relação do significado desses vocábulos-termos com as vivências do amazônida ribeirinho? d) os vocábulos-termos são simbólicos do tema a que se referem? e) influenciam comportamentos e regulam condutas naquela região específica? f) que saberes estão entrelaçados nos significados desses vocábulos-termos?

O contexto geral de uso dos vocábulos-termos, na obra, é o momento em que Luís Chato já se encontra na mata em estado de perdição. Nesse estado, rememora episódios e pequenos eventos que antecederam o seu estado de perdição ao mesmo tempo em que atenta, minuciosamente, para os que ocorrem durante a situação de perdido.

Ao rememorar os episódios anteriores à sua perdição na mata, assume uma postura analítica e reflexiva, na tentativa de compreender seu estado atual, naquele momento. Assim busca explicar para si mesmo: como se dera aquela perdição na mata? O que a desencadeara? Qual fora a sua negligência enquanto mateiro experiente? Quais saberes de sua cultura amazônida havia desprezado? Quais saberes ele deveria reconsiderar?

Nessa atitude reflexiva, Luís chato analisa o que acontecera a sua volta, deixando evidente um conjunto de saberes construídos pelo homem amazônida a partir de sua relação com a floresta. Tais saberes permitem ao homem da região tomar decisões de seu dia a dia a partir de sinais enviados pela própria natureza. Assim, há sinais enviados pela natureza que terminam por advertir o homem acerca do modo adequado de agir em sua relação com natureza, das transgressões que não deve cometer, das sanções aos transgressores, e dos prognósticos da sorte de alguém.

Os sinais enviados pela natureza tanto dizem respeito a questões mais racionais tais como a ocorrência ou não de chuva quanto a questões do campo das crenças, do sobrenatural, para as quais não há uma relação lógica e racional. Logo, as decisões sobre atividades como pescar, caçar e plantar etc. devem considerar os sinais emitidos pela natureza, os quais terminam por influenciar e regular a conduta dos indivíduos.

Importa atentar para o fato de que os significados dos vocábulos-termos foram construídos a partir das vivências do homem amazônida ribeirinho na relação com o ambiente. Desse modo, os vocábulos-termos traduzem a carga simbólica de determinados temas. Assim, na obra, há um conjunto de elementos da fauna interpretados por Luís Chato como tendo estreita vinculação ao seu estado de perdição, 
conforme os significados construídos naquela cultura ribeirinha amazônida. Os vocábulos-termos guariba, tucano, saracura, rã e uru são tomados como prenunciadores de chuva; Já os vocábulos-termos ticoã, camiranga e rasga- mortalha como indicadores de mau presságio, morte e agouro. Trazemos a seguir a relação e análise destes termos selecionados da obra:

\section{- Vocábulo-termo Guariba}

- Guariba Sm. ZOOL V bugio, acepções 1, 2 e 3.

Bugio $^{3}$ Sm. ZOOL Denominação comum aos macacos do gênero Alouatta, da família dos cebídeos, comuns nas florestas da América Latina, de cor escura, pelagem densa e barba espessa no maxilar inferior. São animais arbóreos que se alimentam de folhas e frutos. Etimologia; tupi waríwa.

- Guariba: Animal anunciador de chuva. (Jacob, 1985)

O vocábulo-termo guariba é evocado na narrativa de Chuva Branca com um significado adicional que ultrapassa o significado de "animal". No ambiente da Amazônia, o animal é interpretado como aquele que anuncia a vinda da chuva. Na obra, o ribeirinho Luís Chato temia a chegada do mal tempo, uma vez que poderia prejudicar sua dormida embaixo do rabo de jacu ${ }^{4}$, apagar os rastros e, consequentemente, interromper o encontro de seu caminho de volta para casa. Assim como Luís Chato, há quem diga que os rugidos e roncos do macaco guariba servem como agouro. "Tempo vem vindo, guariba acordou agourando chuva." (JACOB, 1968, p. 83).

O macaco guariba é bastante conhecido nas comunidades ribeirinhas, justamente pela caracterização descrita anteriormente: o de anunciador de chuva. Esse valor cultural está vinculado aos saberes, costumes e crenças reunidos ao longo do tempo por diferentes gerações em certas comunidades, nesse caso, a dos ribeirinhos.

Assim, o vocábulo-termo guariba que, para muitos, significa apenas o animal primata habitante das florestas da Amazônia, naquele contexto específico, traz traços semânticos adicionais como o "anunciador de chuva", o que seria um prenúncio

\footnotetext{
${ }^{3}$ O dicionário consultado apresenta mais três acepções do termo bugio: 2 ZOOL Macaco (Alouatta fusca) encontrado nas florestas do Sudeste do Brasil e do nordeste da Argentina, de pelagem marrom ligeiramente avermelhada; bugio-ruivo, guariba, ruivo; 3 ZOOL Macaco (Alouatta caraya) das florestas da região central da América do Sul, de pelagem preta ou marrom-escura; bugio-preto, carajá, guariba; 4 ZOOL Macaco (Alouatta seniculus) da região amazônica, de pelagem vermelho-escura, com as costas alaranjadas; arauatu, bugio-labareda;

${ }^{4}$ Rabo de jacu: abrigo provisório feito por Luís Chato.
} 
bastante negativo e que faz com que Luís Chato pense em uma solução para a situação crítica que se anuncia, tendo suas ações regidas por aquele significado cultural.

\section{- Vocábulo-termo Tucano}

- Tucano: Sm 1 ZOOL Denominação comum às aves piciformes do gênero Ramphastos, da família dos ranfastídeos, de coloração negra, vermelha, laranja ou verde, plumagem dorsal negra, garganta branca ou amarela e bico muito grande e forte; alimentam-se de frutos e ovos que roubam dos ninhos de outras aves. Etimologia: tupi tukána.

- Tucano: Ave anunciadora de chuva. (Jacob, 1985).

O vocábulo-termo tucano também aparece em Chuva Branca com o significado de prenúncio de chuva. A ave, habitante natural das florestas, é vista pelos amazônidas com a capacidade de chamar chuva por meio de seu canto. Luís Chato, confiante na claridade do tempo, afirma na obra que, ainda que o tucano cante, ele tem certeza de que chuva não cairá (JACOB, 1968). Sua autoconfiança sinaliza um ponto positivo naquele cenário, pois o ribeirinho poderia continuar seu percurso em busca do caminho de volta.

O vocábulo tucano, fora do contexto popular presente em Chuva Branca, não carrega, comumente, a mesma significação que na obra, isto é, o sentido inerente ao seu canto é limitado ao conhecimento de grupos específicos. Vale ressaltar que os saberes de Luís Chato são o que norteiam suas decisões ao longo da narrativa, do início ao fim. Visto como um grande mateiro, o ribeirinho consegue captar diferentes tipos de mensagem, por meio do sol, da terra e dos cantos das aves, entre eles, o do tucano. A interpretação dada ao som que a ave emite como prenúncio de chuva agrega significado adicional ao termo. Assim, o valor etnoterminológico do vocábulo-termo tucano está nos aspectos históricos e culturais da vida dos ribeirinhos, intrinsicamente arraigados em seu significado.

- Vocábulo-termo Saracura

- Saracura: Sf 1 ZOOL - Denominação comum às aves gruiformes, da família dos ralídeos, presentes em todos os continentes, geralmente em locais aquáticos, com vários gêneros e dezenas de espécies, dotados de pernas e dedos longos e destituídos de membranas natatórias. Etimologia; tupi sarakúra 
- Saracura: Ave anunciadora de chuva. (Jacob, 1985)

O vocábulo-termo saracura aparece na obra com o significado daquele que agoura o tempo por meio de seu canto. Para Luís Chato, ao emitir seu som, a saracura estaria chamando chuva - um prenúncio negativo naquela situação. Na narrativa, Luís Chato ao se dar conta de que o dia havia amanhecido bonito e considerando os inúmeros problemas que ele já havia enfrentado, comemora: "A mata tôda branca, sereno do dia. Manhã clara já era, não fôsse a cerração. Sinal de bom tempo, bonzão de calor. Hoje tucano, saracura, uru, podem cantar que chuva não cai." (JACOB, 1968, p. 43). A saracura, além de representar para Luís Chato a vinda da chuva que ele tanto receava, também revela dentro do contexto da obra os inúmeros saberes do ribeirinho.

\section{- Vocábulo-termo R̃̃}

- Rã̃: Sf 1 ZOOL Denominação comum a vários anfíbios anuros de pele lisa, encontrados, em geral, na água ou junto a superfícies aquáticas. Etimologia; lat ranam.

- Rã: Animal agourador de chuva. (Compreensão das autoras baseada na obra).

O vocábulo-termo rã, analogamente aos animais anteriormente citados, carrega o significado de chuva iminente. Mesmo que de forma indireta, Luís Chato refere o anfíbio ao afirmar que sua alegria, que é demonstrada por meio de um som particular, indica mudança de clima, e consequentemente o início de uma tempestade, o que, para ele, não seria conveniente naquele momento, visto que implicaria dificuldades para sua caminhada na busca do varadouro ${ }^{6}$. "Tempo vem vindo, guariba acordou agourando chuva. Rã alegre, com dia claro, outro negócio não é." (JACOB, 1968, p. 83).

Segundo Azevedo (2015), alguns animais, como a rã, podem captar o que está para acontecer com o clima de forma antecipada. O vocábulo-termo rã agrega o significado de prenunciadora de chuva até hoje. Todos esses saberes subliminares à significação dos sons emitidos pelos animais vieram dos antepassados e foram transmitidos por gerações mantendo-se salvaguardados na acepção do vocábulo-termo.

\footnotetext{
${ }^{5}$ No dicionário consultado há outras acepções mais específicas do termo rã: 2 ZOOL Denominação comum aos anfíbios anuros do gênero Rana, da família dos ranídeos, encontrados em praticamente todas as regiões do planeta; rã-verdadeira. 3 ZOOL Denominação comum aos anfíbios anuros da família dos leptodactilídeos, encontrados nas Américas, nas proximidades de rios, lagoas e pântanos; caçote, jia.

${ }^{6}$ Ponto chave de um determinado espaço que marca o local de chegada ou partida. (Compreensão das autoras com base na obra Chuva Branca)
} 
O vocábulo rã é considerado um vocábulo-termo por seu valor cultural e a relevância que carrega. A mensagem que este anfíbio passa por meio de seu "coaxado", reflete e interfere de forma diferenciada na vida de algumas pessoas, que a recebem e a interpretam como um aviso, mais especificamente, como um prenúncio de chuva.

- Vocábulo-termo Uru:

- Uru: Sm ZOOL Ave galiforme florestal (Odontophorus capueira), da família dos fasianídeos, encontrada nas regiões Nordeste, Sudeste e Sul, no sudeste do Mato Grosso, no Paraguai e na Argentina, com aproximadamente $20 \mathrm{~cm}$ de comprimento, grande topete, parte superior castanha com estrias escuras, partes inferiores cinzentas e região dos olhos vermelha. Etimologia: tupi urú.

- Uru: Ave anunciadora de chuva. (Compreensão das autoras baseada na obra)

Luís Chato cita em uma de suas afirmativas o "uru”, ave que, segundo ele, é capaz de pressentir quando a chuva está a caminho. "A chuva vem tomando chegada [...] Uru pressentiu a chegada do mesmo jeito. Bichos que apreciam de ver temporal. " (JACOB, 1968, p. 185). Assim como a rã, o uru aparece na obra como uma forma de avisar, por meio de seus sons, a chegada da chuva. Na obra percebe-se um Luís Chato, conhecedor da mata, utilizando-se de seus saberes para prever e se preparar para o que estaria por vir. A chuva na narrativa, como já referido, é vista como um acontecimento negativo para o ribeirinho, naquela situação de busca pelo varadouro.

Assim como a saracura, a cantoria do uru também garante a vinda da chuva. Tal conhecimento é importante para os ribeirinhos. Assim, a classificação etnoterminológica de $u r u$, está relacionada ao valor cultural que traduz, e à interferência que os significados deste podem causar na forma como os ribeirinhos orientam sua vida.

Os vocábulos guariba, tucano, saracura, rã e uru pertencem ao léxico geral da língua, entretanto, pela simbologia que carregam naquele contexto cultural particular recebem traços de significado que os alçam ao status de vocábulos-termos. Tome-se como exemplo, tucano: a própria "ave" reúne, em si, as características visuais do vertebrado com bico e coberto de penas mas, naquela situação, traduz-se como algo que extrapola esta natureza animal, é visto sob a simbologia cultural de "prenunciador de chuva"; o mesmo ocorre com o vocábulo "uru" que, acrescido desse significado cultural específico compartilhado por aquela coletividade, adquire o status de vocábulo-termo. 
Luís Chato estava envolto por elementos que indicavam fenômenos como a chuva, de modo que a natureza ao seu entorno emanava significados por ele conhecidos e que poderiam orientá-lo na tomada de decisões.

- Vocábulo-termo Ticoã

- Tincoã: Sf REG (AM, PA), ZOOL alma-de-gato, acepção 1. Ave cuculiforme (Piaya cayana), da família dos cuculídeos, encontrada na América Latina, em matas e serrados, com cerca de $45 \mathrm{~cm}$ de comprimento, de plumagem vermelha tirante a castanho nas partes superiores, peito cinza, ventre escuro, cauda longa, escura, bico amarelo e íris vermelha. Etimologia; tupi tikuã.

- Ticoã : Ave responsável por anunciar agouro através de seu canto, isto é, que algo de ruim está prestes a acontecer. (Compreensão das autoras baseada na obra)

No início da narrativa a presença do ticoã surge como um alerta a Luís Chato acerca de acontecimentos ruins que estavam por vir. $\mathrm{O}$ ribeirinho, destemido $\mathrm{e}$ confiante, mesmo tendo conhecimento do que ele próprio considerava como pura superstição por traz do canto da ave, ignora-a e segue em frente em busca da tão desejada "anta". Em Chuva Branca, o canto do ticoã sinaliza coisas negativas. "O ticoã cantou naqueles confins. Azar, vai agourar teu pai e tua mãe. " (JACOB, 1968, p. 15).

O ticoã, também conhecido por muitos como alma-de-gato, alma-perdida ou alma-de-caboclo tem um canto semelhante ao gemido de um gato. Uma das justificativas populares para o canto da ave representar agouro, relaciona-se à natureza triste do canto. Assim, na obra, o vocábulo-termo ticoã, simboliza agouro, azar e influencia as ações do ribeirinho amazônida. Segundo Luís Chato, se tivesse levado em consideração o canto da ave como um aviso, teria evitado o seu estado de $\operatorname{areação~}^{8}$ na mata.

- Vocábulo-termo: Camiranga

- Camiranga: f ZOOL V urubu-de-cabeça vermelha: Urubu (Cathartes aura) encontrado na américa do Norte, na América Central, na América do Sul (Venezuela, Equador, Colômbia, Peru, Chile, Argentina) e em todas as regiões do Brasil em florestas e

\footnotetext{
${ }^{7}$ No dicionário consultado foi registrada a variante tincoã ao passo que, na obra Chuva Branca, está registrada a variante ticoã.

${ }^{8}$ Areação: situação de estar perdido.
} 
campos. Essa ave tem, aproximadamente, $70 \mathrm{~cm}$ de comprimento, cabeça e pescoço vermelhos ou rosados e plumagem negra. Etimologia: tupí kamiránga.

- Camiranga: Ave que representa agouro, a chegada de acontecimentos ruins. (Compreensão das autoras baseada na obra).

O vocábulo-termo camiranga, assim como o apito do matim ${ }^{9}$, carrega o significado de morte dentro do contexto de Chuva Branca. Luís Chato, doente, com fome e já sem expectativas de sobrevivência, relembra que, em uma das noites de sua perdição, percebeu que a ave pousara em seu local de dormida. Logo entendeu a presença como um aviso de sua morte: "Por agouro, pra quem já está liquidado naquela precisa hora, o camiranga ainda pousa em cima do abrigo. Na quase certeza de morrer naquele dia, o desvanecimento que rolou na maginação. " (JACOB, 1968, p. 225).

Na obra, a aparição do camiranga é traduzida como um aviso a Luís Chato sobre o desfecho daquela saga de perdição, ainda que eventos mais concretos como a fome, a ausência da mariposa ${ }^{10} \mathrm{e}$ as demais adversidades enfrentadas por ele já sinalizassem o fim. As crenças de sua comunidade, demonstradas ao longo de seu percurso, aparecem, mais uma vez, neste caso, no valor funesto e negativo atribuído à presença do camiranga.

Segundo o conjunto de conhecimentos que Luís Chato reunira ao longo da vida e inerentes ao lugar onde vivia, e que tão bem conhecia, os elementos da mata, comunicavam-se com o ser humano, dando-lhe indicadores de seu destino. No caso do camiranga: sua morte iminente. O vocábulo camiranga, ao associar-se ao significado cultural de "morte iminente", ultrapassa o significado geral da língua e o de especialidade do campo das aves, atingindo o nível de vocábulo-termo.

- Vocábulo-termo Rasga-mortalha

- Rasga-mortalha ${ }^{11}$ : ZOOL 1 V narceja; 2 REG (AM) V suindara; nar·ce·já sf. ZOOL 1 Ave limícola (Gallinago paraguaiæ), da ordem dos caradriiformes, da família dos

\footnotetext{
${ }^{9}$ Matim: ave que carrega em si e no seu canto, o aviso de uma possível morte de algum ente querido daquele que a vê ou a ouve. (Compreensão das autoras com base na obra Chuva Branca)

${ }^{10}$ Mariposa: arma de caça de Luís Chato.

${ }^{11}$ O dicionário também dá outra acepção para Rasga Mortalha: ZOOL 2 su·in·da·ra: sf ZOOL Coruja de grande porte (Tyto alba), da família dos titonídeos, que atinge cerca de $35 \mathrm{~cm}$ de comprimento, geralmente encontrada em cavernas, torres de igrejas e telhados, em todos os países da América do Sul, de plumagem branca ou pardo-amarelada, cabeça e dorso com manchas marrons e um disco facial amarronzado; coruja-branca, coruja-católica, coruja-das-torres, coruja-de-igreja, corujão-de-igreja,
} 
escolopacídeos, distribuída pela América do Sul, caracterizada pelo bico longo, de pernas compridas, plumagem castanha com listras amareladas e ventre branco; produzem sons vibrantes durante os voos no período reprodutivo. Etimologia: desc.

- Rasga-mortalha: Ave conhecida por muitos como sendo agourenta. Carrega em seu canto o aviso de morte da pessoa que a escuta ou de algum ente querido. (Compreensão das autoras baseada na obra).

Rasga-mortalha, um dos vocábulos-termos mais significativos quando se trata de prenúncio de morte, traz para a obra a ideia de que Luís Chato estaria, definitivamente, fadado a morrer. O ribeirinho, mesmo passando por diversas situações que já o levassem a ter essa percepção, “confirma” seu pensamento quando escuta a coruja cantar: "Coruja cantando mata adentro, enchendo os arredores das terras gerais. Da boa de azalação, rasga-mortalha, aviso de morte. " (JACOB, 1968, p. 245).

Assim como em Chuva Branca, nas regiões norte e nordeste do Brasil, construiu-se, ao longo do tempo, a crença de que o canto da rasga-mortalha, semelhante a um grito, prenuncia a morte de quem o escuta ou de algum familiar próximo (PESSOA, 2013). O vocábulo-termo traduz, na obra, o indesejável e iminente futuro de Luís Chato que, ao final, fica subentendido.

Nota-se que o significado cultural e simbólico é o que confere a esses vocábulos o estatuto de especialidade e, por conseguinte, o de vocábulo-termo. Os vocábulostermos selecionados neste estudo, ao mesmo tempo em que mantém a referência ao animal, são indicadores culturais de prenúncio de chuva ou de morte.

\section{Considerações finais}

A força simbólica dos vocábulos-termos presentes em Chuva Branca, faz da obra um repertório de cenas e eventos capazes de traduzir muitos aspectos da identidade do homem amazônida. Para além disso, o valor de significado agregado a cada vocábulo é uma demonstração do vasto conjunto de saberes dos povos amazônidas e a importância desse conhecimento para a sobrevivência local. As plantas, os animais e

mocho-das-cavernas, rasga-mortalha, sondaia, suiná, suinara, suindá, tuidara, tuindá. Etimologia: tupi suindára 
até o tempo, ganham em Chuva Branca valores significativos, que não poderiam ser conferidos se não pelo conhecimento das experiências e valores dos ribeirinhos amazônidas e seus saberes tradicionais.

A obra literária Chuva Branca é a demonstração clara do quanto a literatura pode atuar como fonte de revelação e divulgação da cultura de um dado local e para a formação de uma sociedade de leitores críticos e conhecedores do pluralismo linguístico e cultural que se faz presente nas regiões brasileiras. A língua, os costumes e as crenças dos ribeirinhos amazonenses aparecem em Chuva Branca em um contexto peculiar, permitindo que o leitor tenha acesso à diversidade de informações ainda que ausente do espaço amazônico.

A pesquisa reitera o que tem sido estudado e afirmado sobre a estreita relação entre léxico e cultura e reforçamos, com este trabalho, que os vocábulos-termos são uma forte evidência e representação dessa relação. Os vocábulos-termos considerados no presente trabalho constituem uma demonstração de como um determinado vocábulo, mantendo os traços de seu significado geral dicionarizado, ao serem usados por um determinado grupo social, em dado contexto, agregam significados especiais, simbólicos de saberes e de valores reguladores da vida social, elevando-se, assim, à condição de termo. Representam, assim, com bastante propriedade, a relação entre léxico e cultura e, em instância maior, entre língua e realidade.

\section{REFERÊNCIAS}

AZEVEDO, Thais. 5 animais que conseguem prever tempestades, 2015. Disponível em: 〈https://www.vix.com/pt/bbr/894/5-animais-que-conseguem-prever-tempestades>. Acesso em: 8.7. 2019.

BARBOSA, Maria Aparecida. TERMINOLOGIA E LEXICOLOGIA: plurissignificação e tratamento transdisciplinar das unidades lexicais nos discursos etnoliterários. Revista de Letras/ Ceará -v. 1, n. 27, 11. p. 103-107. 2005. Disponível em: http://www.periodicos.ufc.br/revletras/article/view/2298/1768. Acesso em: 20. 12. 2019.

BARBOSA, Maria Aparecida. PARA UMA ETNO-TERMINOLOGIA: Recortes Epistemológicos. Ciência e Cultura. São Paulo. Cult. vol.58. n.2. p. 48-51, 2006. Disponível em: $\langle$ http://cienciaecultura.bvs.br/scielo.php?script=sci_arttext\&pid=S000967252006000200018>. Acesso em: 12. 7. 2019. 
BARBOSA, Maria Aparecida. In: ISQUERDO, Aparecida Negri; ALVES, Ieda Maria. (Org.). As ciências do léxico. Lexicologia, Lexicografia. Terminologia. $1^{a}$. ed. Campo Grande, MS: Ed. UFMS. 2007. p. 13-22.

BARBOSA, Maria Aparecida. CULTURA POPULAR AMAZÔNICA EM ETNOTERMINOLOGIA. Anais da $61^{\text {a }}$ Reunião Anual da SBPC - Manaus, AM - Julho/2009. Disponível em: http://www.sbpcnet.org.br/livro/61ra/simposios/SI_MariaBarbosa.pdf. Acesso em: 5. 3. 2020.

BIDERMAN, Maria Tereza Camargo. A estrutura mental do Léxico. In: QUEIROZ, T. A (Ed.) ESTUDOS DE FILOLOGIA E LINGÜÍSTICA: em homenagem a Isaac Nicolau Salum. São Paulo: Editora da Universidade de São Paulo, 1981.

CHAVES, Maria P. S. R. UMA EXPERIÊNCIA DE PESQUISA-AÇÃO PARA GESTÃO COMUNITÁRIA DE TECNOLOGIAS APROPRIÁDAS NA AMAZÔNIA: O estudo de caso do assentamento de Reforma Agrária Iporá. Tese (Doutorado em Política Científica e Tecnológica) - Unicamp, Campinas, SP. 2001.

COUTINHO, Afrânio. Notas de teoria literária. 2. ed. Rio de Janeiro, Civilização Brasileira, 1978. p. 9-10.

GENETTE, Gérard. Discurso da narrativa. Tradução: Fernando Cabral Martins. 3. Ed. Lisboa: Veja, 1995.

IMAZON. A FLORESTA HABITADA: História da ocupação humana na Amazônia. Belém, 2015. Disponível em: <https://imazon.org.br/a-floresta-habitada-historia-daocupacao-humana-na-amazonia/>. Acesso em: 1. 4. 2019.

JACOB, Paulo. Chuva branca. Rio de Janeiro: Gráfica Record Editora, 1968.

JACOB, Paulo Dicionário da língua popular da Amazônia. Rio de Janeiro: Editora Cátedra, 1985.

LATORRE, Vanice Ribeiro Dias. A DIALÉTICA ENTRE OS EXTREMOS: da terminologia à etnoterminologia. Caderno Seminal Digital. Rio de Janeiro, vol. 19. n. 19. p. 70- 94, 2013.

MENDONÇA, R. Memórias amazonenses, (2012). Disponível em: <http://catadordepapeis.blogspot.com.br/2012_02_01_archive.html>. Acesso em: 15 . 12. 2019.

PEIXOTO, Fabrícia. Linha do tempo: Entenda como ocorreu a ocupação da Amazônia. BBC- NEWS/ BRASIL. Brasília, 2009. Disponível em: <https://www.bbc.com/portuguese/noticias/2009/07/090722_amazonia_timeline_fbdt $>$. Acesso em: 1. 4. 2019. 
PORTUGUESA, Michaelis Moderno dicionário da Língua. São Paulo/ SP. Editora Melhoramentos. 2015. Disponível em: https://michaelis.uol.com.br/modernoportugues/ Acesso em: 4. 3. 2020.

POTTIER, Bernard; AUDUBERT, Albert; PAIS, Cidmar Teodoro. Estruturas linguísticas do português. São Paulo: Difusão Europeia do Livro, 1972.

SCHONTAG, José Antonio. OS INCENTIVOS FISCAIS DA ZONA FRANCA DE MANAUS: As matérias-primas regionais para produção de "concentrados". FGV Projetos Artísticos, 2015.

SILVA, Ana Zélia. Usina de letras. Saudação ao desembargador Paulo Herban Maciel Jacob. $\quad$ Manaus, $2010 . \quad$ Disponível em: http://www.usinadeletras.com.br/exibelotexto.php?cod=3973\&cat=Discursos.

Acesso em: 9. 3. 2020.

SOUZA, Jamescley Almeida de. PAULO JACOB: uma fortuna crítica, 2015. O GariRevista Eletrônica de Literatura. Disponível em: <http://oguari.blogspot.com/p/paulojacob-uma-fortuna-critica.html>. Acesso em: 09. 07. 2019.

VILELA, Mário. Léxico e gramática. Coimbra: Almedina, 1994. 